\title{
Os 30 Anos do SUS e do Modelo de Atenção ao Câncer retratados na RBC
}

doi: https://doi.org/10.32635/2176-9745.RBC.2018v64n2.70

The 30 Years of SUS and the Model of Cancer Care portrayed in RBC

Los 30 Años del SUS y del Modelo de Atención al Cáncer retratados en la RBC

Alessandra de Sá Earp Siqueira'; Anke Bergmann²; Leticia Casado³; Mario Jorge Sobreira da Silva ${ }^{4}$; Mauro Musa Zamboni ${ }^{5}$

Ao longo dos seus 30 anos, o Sistema Único de Saúde (SUS) se sustentou como um dos sistemas mais democráticos e inclusivos do mundo. Seus princípios e diretrizes têm garantido a ampliação da oferta e do acesso aos serviços e açôes de saúde, impactando na qualidade e no aumento da expectativa de vida da população brasileira ${ }^{1}$. Nesse período, a estruturação e a organização do modelo de atenção ao câncer teve lugar de destaque na agenda política².

O contexto atual mostra o impacto do câncer sobre a carga de doenças e agravos não transmissíveis (DANT) e aponta para a necessidade mundial de repensar as estratégias governamentais de atenção à saúde populacional. O câncer se tornará a principal causa de morte por doença no mundo e já é considerado a principal barreira para o aumento da expectativa de vida da população no século $\mathrm{XXI}^{3}$. Sendo assim, é preciso pensarmos estratégias para superação desse obstáculo.

Para ressaltar a relevância desse contexto, a Revista Brasileira de Cancerologia (RBC), como parte da sua política editorial, nessas últimas três décadas, tem publicado importantes artigos científicos que destacam os avanços e os desafios nas açôes e serviços de atenção ao câncer no SUS e seus efeitos nos indicadores de saúde relacionados.

Como destaques, desde a promulgação da Constituição de 1988 e a criação do SUS, a RBC atua de forma estruturada, liderando a discussão e promovendo conhecimento sobre a política e as açóes de controle do câncer 2,4,5, além de publicar artigos que avaliam o impacto dessa história nos últimos 30 anos $^{2}$.

Atuando em consonância com os princípios do SUS de universalização ${ }^{6,7}$, equidade ${ }^{8}$ e integralidade ${ }^{9,10}$, a RBC vem priorizando a publicação de trabalhos direcionados a problematizar e a propor alternativas para os desafios existentes no modelo de atenção ao câncer no Brasil. Além disso, são vistos como prioritários estudos sobre incorporação ou avaliação de inovaçóes realizadas em toda linha de cuidado ao indivíduo com câncer, apontando melhorias nas estratégias de prevençãa $^{8,9}$, diagnóstico precoce ${ }^{10}$, tratamento ${ }^{11}$ e cuidado ao paciente em fim de vida ${ }^{12}$.

Considerando que, para estruturar um sistema de saúde capaz de superar iniquidades na área da atenção ao câncer, se faz necessário ter profissionais/trabalhadores altamente qualificados ${ }^{13}$ e desenvolver pesquisas sustentáveis e inovadoras ${ }^{14}$, também é interesse da RBC a publicação de artigos que versem sobre tais temas.

Neste fascículo, com intuito de ampliar essa discussão, seráo publicados três artigos de opinião redigidos por pesquisadores especialistas no tema, além de outros estudos que contribuem substancialmente para a compreensão do modelo de atenção ao câncer no SUS.

A RBC, comprometida com a ciência, com os direitos do cidadáo e com a melhoria das condiçóes de vida dos indivíduos com câncer, pretende continuar colaborando com esse debate, sendo um canal de disseminaçáo de opinióes, análises, avaliaçôes, e proposiçôes sobre o tema, fomentando o diálogo interdisciplinar e intersetorial por meio da produção científica no campo da cancerologia.

\section{REFERÊNCIAS}

1. Paim JS. Sistema Único de Saúde (SUS) aos 30 anos. Ciênc Saúde Coletiva. 2018; 23(6):1723-8.

2. Silva MJS, Lima FLT, O’dwyer G, Osorio-de-Castro CGS. Política de Atenção ao Câncer no Brasil após a Criação do Sistema Único de Saúde Cancer. Rev Bras Cancerol. 2017;63(3):177-87.

3. Bray F, Ferlay J, Soerjomataram I, Siegel RL, Torre LA, Jemal A. Global Cancer Statistics 2018: GLOBOCAN Estimates

'Editora-Associada. Revista Brasileira de Cancerologia (RBC). Instituto Nacional de Câncer José Alencar Gomes da Silva (INCA). Rio de Janeiro (RJ), Brasil. E-mail: asiqueira@inca.gov.br. Orcid ID: https://orcid.org/0000-0003-3852-7580

${ }^{2}$ Editora-Científica. RBC/INCA. Rio de Janeiro (RJ), Brasil. E-mail: abergmann@inca.gov.br. Orcid ID: https://orcid.org/0000-0002-1972-8777

${ }^{3}$ Editora-Executiva. RBC/INCA. Rio de Janeiro (RJ), Brasil. E-mail: leticiac@inca.gov.br. Orcid ID: https://orcid.org/0000-0001-5962-8765

${ }^{4}$ Editor-Associado. RBC/INCA. Rio de Janeiro (RJ), Brasil. E-mail: mario.silva@inca.gov.br. Orcid ID: https://orcid.org/0000-0002-0477-8595

${ }^{5}$ Coordenador de Ensino do INCA. E-mail:mzamboni@inca.gov.br. Orcid ID: https://orcid.org/0000-0001-6200-6844 
of Incidence and Mortality Worldwide for 36 Cancers in 185 Countries. CA Cancer J Clin. 2018 Nov;68(6):394-424.

4. Kligerman J. Fundamentos para uma política nacional de prevenção e controle do câncer. Rev Bras Cancerol. 2002;48(1):3-7.

5. Temporão JG. Editorial. Normas e Recomendaçôes do INCA. Rev Bras Cancerol. 2003;49(4):201-02.

6. Santini LA. Editorial. Uma vacina à procura de uma política. Rev Bras Cancerol. 2007;53(4):403-04.

7. Mendonça GAS. Câncer no Brasil: um risco crescente. Rev Bras Cancerol. 1992;38(4):167-76.

8. Abreu E, Lopes ER. Projeto de expansão da prevenção e controle do câncer cérvico-uterino: plano de trabalho quinquenal; 1988 a 1983. Rev Bras Cancerol. 1988;34(4):209-19.

9. Romero LC, Costa e Silva VL. 23 Years of Tobacco Control in Brazil: the 1988 Brazilian Tobacco Control Program Today. Rev Bras Cancerol. 2011;57(3):191-211.

10. Baron M, Souza LMBM. Rede de atenção oncológica: como a estratégia saúde da família se percebe na assistência ao paciente com câncer. Rev Bras Cancerol. 2012;58(2):277-77.

11. Kligerman J. Avaliação da assistência oncológica. Rev Bras Cancerol. 2002;48(4):481-84.

12. Instituto Nacional de Câncer (BR). Cuidados paliativos oncológicos, controle de sintomas: condutas do INCA. Rev Bras Cancerol. 2002;48(2):191-211.

13. Silva MGC, Arregi MMU. Residência médica na área de cancerologia no Brasil: distribuição dos programas e da oferta de vagas por região em 2003. Rev Bras Cancerol. 2005;51(1):5-13.

14. Kligerman J. Pesquisa médica e incorporação tecnológica. Rev Bras Cancerol. 2003;49(1):3-4. 